Avoimesti luettavissa osoitteessa http://journal.fi/ainedidaktiikka

\title{
Kestävä kädenjälki käsityössä
}

\author{
Niina Väänänen ja Sinikka Pöllänen \\ Filosofinen tiedekunta, Itä-Suomen yliopisto
}

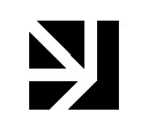

Käsitepari kestävä käsityö on syntynyt käsityön vastaukseksi kestävän kehityksen haasteisiin. Tässä teoreettisessa kirjallisuuskatsauksessa tarkastelemme käsityötä mahdollisuutena kestävään kädenjälkeen. Ensin pohjustamme keskustelua kirjallisuuden avulla, minkä jälkeen syvennymme kestävän käsityön käsitteeseen sekä avaamme näkökulmia kestävään käsityöhön perusopetuksen käsityössä. Kestävän käsityön teoreettisessa mallissa kuvataan käsityötä toimintana, tuotteena ja aineettomana käsityönä. Kestävää käsityötä toimintana kuvataan käsityötietoa syventävänä sekä arvoja ja asenteita muokkaavana taitona. Kestävä käsityötuote puolestaan huomioi materiaalien, elinkaaren, tekniikan, designin, laadun, esteettisyyden, tarpeen ja tuotesuhteen. Aineeton käsityö nivoo kestävyyden ympäristön lisäksi kulttuuriin sekä sosiaaliseen, taloudelliseen, psykologiseen, yhteiskunnalliseen, filosofiseen ja kommunikatiiviseen näkökulmaan. Nämä elementit toimivat lomittain yhdessä muotoillen ympäristöä, konkreettisia tuotteita sekä tekoja kestäväksi ekologiseksi kädenjäljeksi, mikä tulisi olla lähtökohtana myös käsityönopetuksessa kaikilla koulutusasteilla.

Aineeton käsityö, kestävä kehitys, käsityötuote, käsityötaito, ekologinen kädenjälki

Lähetetty: 15.2.2020

Hyväksytty: 20.3.2021

Vastuukirjoittaja: niinavaan@gmail.com

DOI: $10.23988 /$ ad. 89677 


\section{Johdanto}

Olemme siirtyneet ilmastonmuutoksesta eko-kriisin aikakaudelle (Saari \& Värri, 2017), jossa ihmisten toimet vaikuttavat ennennäkemättömästi ympäröivään maailmaan. Kestävä kehitys on laaja vastaus tähän maailmanlaajuiseen ongelmaan. Kestävän kehityksen varjopuoli onkin juuri sen kaikenkattavuus ja käsitteen abstraktius. Siitä voi olla vaikea saada kiinni ja ymmärtää, mitä se tarkoittaa omassa toimintaympäristössä. Kirjallisuuden ja tutkimusten perusteella kestävää kehitystä on käsitteenä tarkasteltu sosiaalisesta, taloudellisesta ja ympäristön näkökulmista, mutta keskustelua voidaan käydä myös poliittisesta ja henkisestä näkökulmasta (Leal Filho, Manolas \& Pace, 2015). Lähtökohtaisesti kestävä kehitys -keskustelu on poliittista, sillä se ajaa yhteisön etua säilyttää tulevaisuuden elinolosuhteet sellaisina, että kaikenlainen elämä on maapallolla mahdollista. Tätä poliittista keskustelua koordinoi Yhdistyneet Kansakunnat (YK). YK:n jäsenmaat ovat kuvanneet Agenda 2030 -ohjelmaansa 17 kestävän kehityksen tavoitetta. Nämä tavoitteet kohdistuvat ihmisiin, maapalloon, vaurauteen, rauhaan ja kumppanuuteen liittyviin kysymyksiin (United Nations, 2015).

Nykyisin voidaan puhua ekososiaalisesta sivistyskäsityksestä kestävän kehityksen sijaan. Salonen ja Bardy (2015) näkevät ekososiaalisen sivistyskäsityksen perustuvan päätöksenteon hierarkiaan, jossa ekologiset kysymykset ovat ensisijaisia, ihmisoikeuskysymykset seuraavia ja vakaan talouden vaaliminen kolmannella sijalla päätöksenteossa, missä arvopohjana on vastuullisuus, kohtuullisuus ja ihmisten välisyys. Toisin sanoen ihmiset ovat toisistaan ja luonnosta riippuvaisia ja elävät yhteen kietoutuneissa systeemeissä. Voidaan myös katsoa, että on olemassa heikkoa ja vahvaa kestävän kehityksen keskustelua (Salonen, 2019). Heikko keskustelu keskittyy yksittäisiin asioihin, kun vahva keskustelu puolestaan käsittelee kokonaisuuksia ja niiden suhteita. Tieteen tavoitteena on selkeyttää moniulotteisia kokonaisuuksia pilkkomalla niitä helpommin hallittaviin osiin. Koska maapallon kantokyky on rajallinen ja yhteisiä huolenaiheita aiheuttaa fyysisesti resurssien riittäminen, ilmastonmuutos, väestönkasvu sekä konflikteja aiheuttavat ihmisten keskinäiset suhteet ja arvomaailmojen yhteen törmääminen, on aika puhua kulttuurin muutoksesta. Jälkimateriaalisissa hyvinvointiyhteiskunnissa voisimme etsiä tasapainoa omistamisen (engl. having) sijaan olemisesta (engl. being) (Ehrenfeld, 2014; Salonen, 2019). Nämä ovat jaloja päämääriä, mutta meidän tulisi ensin ymmärtää kulttuuria ja niitä tapoja, joihin muutosta kaivataan sekä etsiä kestäviä tähän päivään ja tulevaisuuteen kytkeytyviä keinoja muutokseen elämän eri osa-alueilla.

Yhtenä konkreettisena esimerkkinä ja toimintaan tähtäävänä symbolina voidaankin pitää ekologinen kädenjälki -käsitettä (engl. ecological handprint) (Biemer, Dixo, \& Blackburn, 2013; Hayward, 2010). Ekologinen kädenjälki -käsitteen avulla voidaan keskittyä lisäämään sellaisia kestäviä toimia, joilla on positiivisempi vaikutus kuin esimerkiksi kielteisten vaikutusten toimiin, resurssien ja ympäristökuorman vaikutuksiin 
keskittyvässä jalanjälki-ajattelussa (engl. footprint). Näin otetaan huomioon tuntevan, tekevän ja osaavan käden jälki (ks. Räisänen, Kouhia \& Kärnä-Behm, 2014) rakentavana lähestymistapana, joka keskittyy mahdollisuuksiin eikä ongelmiin (Hayward, 2010). Kädenjälki-metaforan tarkoituksena on osoittaa, millaisia positiivisia kestävyyteen tähtääviä toimia tulisi ottaa käyttöön ja kannustaa niiden mukaisiin toimiin, ohjata punnitsemaan esimerkiksi hiilijalanjäljen tuomia vaikutuksia ja toimintarajoitteita mutta lisäten niihin kädenjäljen tuomia lisäarvoja (ks. Guillaume ym., 2020). Räisänen ja muut (2014) käyttävät kädenjälki-metaforaan rinnastettavaa käsitettä fingerprint. Kehitetyn Fingerprint-työkalun avulla voidaan arvioida kestävyyden ja käytettävyyden osa-alueita, esimerkiksi ekologisen kestävyyden osa-alueen yhteyttä tuotteen käyttöikään. Edellä kuvattujen kädellisyyteen, inhimilliseen toimijaan (ks. KojonkoskiRännäli, 2014) viittaavien käsitteiden voidaan nähdä olevan oleellinen osa käsityötä ja käsityön opetusta, jolloin syntyy pragmaattinen tarve avata tarkemmin, mitä kestävä kädenjälki käsityössä tarkoittaa.

Tämä teoreettinen kirjallisuuskatsaus kestävästä kädenjäljestä käsityössä hyödyntää aikaisempaa aiheesta olevaa kirjallisuutta tehden siitä syntetisoivia johtopäätöksiä ja luoden uusia näkökulmia (ks. Coughlan, Cronin, \& Ryan, 2013). Kirjallisuutta on haettu kattavasti eri tietokantojen avulla (Finna, Eric) hakusanoilla kestävä käsityö, sustainable craft, ecological handprint, ecological handprint AND crafts, ekologinen kädenjälki, käsityön opetus ja kestävä kehitys, käsityön opetus, jolloin on saatu laaja otos kotimaista ja kansainvälistä tieteellistä kirjallisuutta kestävään kehitykseen ja sen käsitteistöön sekä käsityön opetukseen liittyen. Tässä artikkelissa käytetyn narratiivisen kirjallisuuskatsauksen tarkoituksena on syntetisoida aiheesta saatavilla olevaa tietoa (Paré \& Kitsiou, 2017). Tämän tyyppinen kirjallisuuskatsaus toimii hyvin kirjallisuuden syntetisoinnissa, tutkimustarpeen tunnistamisessa ja käsitteellisen viitekehyksen luomisessa (Paré \& Kitsiou, 2017). Kirjallisuuskatsauksessa tarkastelemme käsityötä mahdollisuutena kestävään kädenjälkeen. Ensin pohjustamme keskustelua kirjallisuuden avulla, minkä jälkeen syvennymme kestävän käsityön käsitteeseen sekä avaamme näkökulmia kestävään käsityöhön perusopetuksen käsityössä.

\section{Käsityö mahdollisuutena kestävään kädenjälkeen}

Käsityön moniulotteiset mahdollisuudet voivat tarjota yhden areenan kestävän kädenjäljen edistämiselle ja kestävän kasvatuksen toimintaympäristön. Käsityössä on mahdollista huomioida usealla eri tavalla ja tasolla kestävän kehityksen periaatteet (Suojanen, 2001). Käden taidot liittyvät syvästi ihmisyyteen ja ihmiskunnan kehitykseen, jolloin käsityö on arjen luonnollisena, käyttäjälähtöisenä toimintana rakentunut jo lähtökohdiltaan kestävän kehityksen toimintaperiaatteille (ks. Dissanayake, 1995; Kojonkoski-Rännäli, 2014). Konkreettisen tuotteen valmistamisen, valmistustekniikan tai työvälineen käytön oppimisen lisäksi käsityö on aina ollut myös sisäisiä kvalifikaatioita kasvattavaa prosessi, jossa yksilö on saanut valmiuksia toimia vastuullisena ja järkevästi ajattelevana kansalaisena omassa yhteisössään (Pöllänen \& Kröger, 2000). Käsityön merkitys on alkuperäisestä tarvelähtöisestä valmistuksesta muuttunut, mutta tästä huolimatta käsityöllä on edelleen oma sijansa esimerkiksi kulttuurina, 
elinkeinona, oppiaineena ja tänä päivänä myös omasta näkökulmastaan kestävyyttä tutkivana tieteenalana (Ihatsu, 2002; Pöllänen \& UrdziṇaDeruma, 2017; Väänänen \& Pöllänen, 2020).

Vaikka käsityön kulttuurinen rappeutuminen ja murros aiheuttavat huolta (Kokko \& Kaipainen, 2015), on käsityön nähty myös avaavan mahdollisuuksia parempaan maailmaan sekä demokraattisempiin toimintamalleihin (Åhlvik \& von Busch, 2009). Niin kutsutun tavallisen käsityön (Ihatsu, 2002) ja psykologista hyvinvointia tuottavan harrastamisen (Corkhill, Hemmings, Maddock, \& Riley, 2014; Pöllänen, 2015a, 2015b) rinnalle on noussut yhteisöllinen käsityö osallistavana käsityöprosessina (Kouhia, 2015; Vartiainen, 2010). Yhdessä tekeminen tai oman käsityön näkyväksi saattaminen sitouttaa ja antaa tunteen kuulluksi tulemisesta ja osallisuudesta (Lindström \& Ståhl, 2014). Näin myös käsityön yhteisöllisyys voidaan nostaa kestävän käsityön yhdeksi näkökulmaksi. Erityisesti käsityö-aktivismissa, craftivismissa, yksilön omien ajatusten ilmentyminen sekä kädentaitoina että vaatimusten ilmaisuna on nähty pehmeänä ja vuorovaikutuksellisena yhteiskunnallisena vaikuttamistapana (ks. Garber, 2013; Greer, 2014). Sosiaalinen media ja sen kautta saatava samauttava keskustelu ja verkostoituminen on sekä vahvistanut käsityön tekemistä (mm. von Busch, 2010; Valtchannov, Perry, Glover \& Mulcahy, 2016) että myös luonut yhteiskehittelyä ja uutta teknologiaa hyödyntäviä mahdollisuuksia uudistaa käsityötä (Stuedahl \& Mörtberg, 2012; Tung, 2012). Käsityö voi toimia välittäjänä eri aikakausien, kulttuurien ja ihmisten välillä (Pöllänen, 2015a). Koska käsityö ei synny ilman tekijää, on käsityöntekijä ja hänen toimintansa keskiössä, kun arvioidaan kestävyyttä ja tasapainoa. Käsityöntekijä tekee päätöksiä, joilla on vaikutuksia tuotteeseen, toimintaan ja ympäristöön (Väänänen ym., 2016). Näin käsityöntekijän arvot ja asenteet muokkaavat käsityötä ja toimintaa toivottuun suuntaan (ks. Räisänen ym., 2014).

Nopeaan muodin kiertoon ja kasvavaan kulutukseen perustuva elämäntapa on alettu yhä laajemmin nähdä ympäristökysymysten lisäksi niin epädemokraattisena ja osallisuudesta ulossulkevana (von Busch, 2018) kuin myös ulkonäköön liittyvien paineiden takia hyvinvointia nakertavana (Grogan, 2008). Design-ajattelu on nähty yhtenä mahdollisuutena käyttäjät huomioiviin ja osallistaviin suunnittelu- ja toimintatapoihin taloudellisten tulostavoitteiden sijaan (von Busch, 2018; von Busch \& Palmås, 2016). Fletcher (2008) korostaakin sellaisten ratkaisujen kehittämistä, missä painopistettä siirretään käytänteistä, jotka horjuttavat ihmisten, ympäristön tai yhteiskunnan hyvinvointia, kohti sellaisia käytänteitä, jotka vahvistavat hyvinvointia. Näin esimerkiksi kestävä tai hidas muoti pyrkii kokonaisvaltaisesti parempiin toimintatapoihin ja erityisesti suunnittelemaan ja valmistamaan vaatteet kestävällä tavalla (Aakko, 2012). Soini-Salomaa (2013) nostaa esiin kestävän kehityksen keskeisenä käsityöalan tulevaisuuden teemana ja käsityöyrittäjyyden kantavana voimana. Loppujen lopuksi, vaikka tuote olisi suunniteltu ja valmistettu kestävän kehityksen periaatteiden mukaan, on kuluttajan ostopäätöksellä (Markkula, 2011) ja tuotteen käyttäjän toiminnalla (Aakko, 2012) suuri merkitys kestävyyden näkökulmasta. 


\section{Kestävä käsityö systeeminä}

Papanek $(1973,1995)$ on painottanut suunnittelijan vastuuta ja tuotteiden suunnittelussa turhan välttämistä jo 1970-luvulta lähtien. Nämä kysymykset ovat edelleen ajankohtaisia yli puoli vuosisataa myöhemmin kestävästä käsityöstä käytävässä keskustelussa. Keskeisiä teemoja ovat menettely- ja toimintatapoihin, talouteen ja markkinoihin sekä materiaaleihin, menetelmiin ja elinkaareen keskittyvät aiheet (Väänänen \& Pöllänen, 2020). Näitä voidaan tarkastella erillisinä keskustelualueina, vaikka ne ovat yhteen kietoutuneita ja erottamattomia kokonaisuuksia (vrt. Ceshin \& Gaziulusoy, 2016).

Menettely- ja toimintatapoihin liittyvät puheenvuorot käsittelevät kestävää käsityötä yhteiskunnan, kulttuurin tai yksilön tasolla. Yhteiskunnallisessa keskustelussa esiin nousee käsityön opetuksen merkitys (Muya, Price \& Edum-Fotwe, 2006; Vartiainen \& Kaipainen, 2012). Kulttuuritasolla kestävän käsityön nähdään yhtäältä nojaavan käsityöperinteeseen ja tukevan käsityön jatkuvuutta (Dillon \& Kokko, 2017), mutta toisaalta se nähdään keinona välittää arvoja ja kannanottoja sekä uudistaa perinteitä teknologiaa hyödyntämällä (Kuusk, Wensveen \& Tamico Plasencia, 2016). Yksilötasolla voidaan tarkastella tekijän taitojen, tietojen ja arvojen suhteita ympäröivään maailmaan.

Talouden ja markkinoiden näkökulmasta kestävä käsityö keskittyy käsityöhön toimialana, erityisesti yrittäjyyden ja artisaanituotannon näkökulmasta. Yritysosaamisena käsityön ja design-toiminnan yhteistyö tarjoaa mahdollisuuksia kehittää toimintaa (Zhan, Walker, HernandezPardo \& Evans, 2017) ja mentorointi sekä business-inkubointi voivat toimia nosteena käsityöyrittämiselle (Farrer \& Watt, 2015; Yair \& Schwarz, 2011). Käsityön jatkuvuutta voi tukea tarinallisuus markkinointistrategiana arvon lisäämisenä tuotteeseen tai palveluun (Luutonen, 2007). Vaikka liiketoimintaverkostojen ja markkinoiden on havaittu osaksi siirtyneen internetiin, näkyy käsityö toimialana edelleen perinteisinä kivijalkamyymälöinä ja kiertävien käsityön ammattilaisten toimintana (Parts, Rennu, Jääts, Matsin \& Metslang, 2011).

Materiaalit ovat välttämätön edellytys käsityön valmistamiselle ja ne ovat tällöin myös oleellinen osa kestävän tuotteen laatua, designia ja estetiikkaa. Kestävän käsityön yhteydessä materiaalit ja elinkaari -teemana voidaan tarkastella myös luonnonmateriaaleja, niiden ominaisuuksia ja kasvupaikkoja, esitellä menetelmiä tai uusio-raaka-aineita (engl. upcycling), joita voi käyttää tuotannossa (Le ym., 2016; Sung \& Cooper, 2015; Wolfe Wilson, 2010). Itse tuotteen elinkaari nähdään syklisenä, luonnonkiertokulkua matkivana prosessina (Väänänen, 2020). Elinkaaren alkupäässä voidaan arvioida materiaalien hankintaan liittyvää toimintaa ja toimintojen tehostamista (Wood, 2011). Tällöin tarkastelussa painottuu ympäristön näkökulma ja siihen vaikuttavat ihmisen toiminnot. Räisäsen ja muiden (2014) mukaan suunnittelun ja arvojen näkökulmasta tuotteen käytettävyys on kestävän käsityön keskeinen arvo. Vaikka tuotteen elinkaari tulisi ottaa huomioon jo suunnitteluvaiheessa, voidaan itse käyttäjän toiminnoilla vaikuttaa elinkaaren pituuteen (König, 2013) ja tuotteen uudelleen kiertoon (Sherburne, 2009). 
Ainedidaktiikka 5(2) (2021)

Tässä artikkelissa kestävän käsityön käsitettä ja sen systeemisyyttä konkretisoidaan myös toimintana, tuotteena ja aineettomana käsityönä. Kestävä käsityö itsessään on monisäikeinen käsite, joka yhdistää kestävä kehitys -käsitteen sekä käsityön käsitteistön teoreettisesti. Näin ollen muodostuu laaja kokonaisuus, jota voidaan kuvata systeeminä (Väänänen, Pöllänen, Kaipainen \& Vartiainen, 2017). Kestävän käsityön systeemi sisältää seuraavat kolme elementtiä: käsityö toimintana, tuotteena ja aineettomana käsityönä (ks. kuvio 1). Näillä jokaisella elementillä on ominaisuuksia, joiden avulla voidaan tarkastella kestävää käsityötä kokonaisuutena yksityiskohtaisemmin.

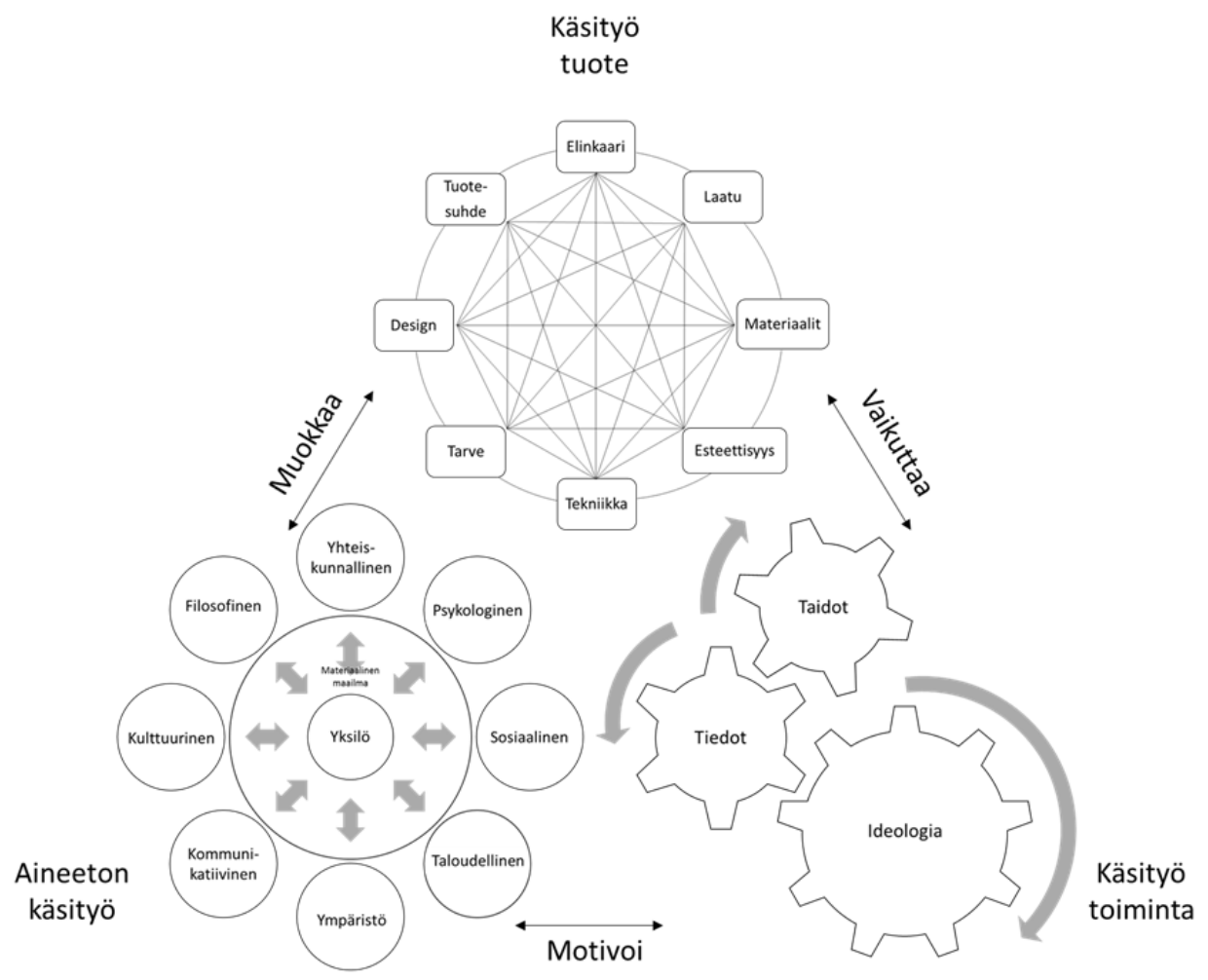

Kuvio 1. Kestävän käsityön systeemi (julkaistu alun perin Väänänen ym., 2017).

Kestävä käsityö toimintana on taitojen, tietojen ja ideologian muodostama ihmiseen liittyvä elementti. Toiminta alkaa erilaisten käsityötaitojen kerryttämisestä. Taitojen ohella tekijä kartuttaa tietoja esimerkiksi materiaaleista, erilaisista rakenteista ja niiden toimivuudesta yritysten ja erehdysten myötä, kunnes taidot ja tiedot ovat hallussa (Dormer, 1994; Groth, 2017; Huotilainen, 2019). Taidot ja tiedot muokkaavat myös tekijän ajatusmaailmaa eli ideologiaa, joka koostuu arvoista ja asenteista (Kojonkoski-Rännäli, 2014). Nuo arvot ja asenteet ovat ympäristöön, tuottamiseen ja tekemiseen liittyviä eettisiä kysymyksiä, esimerkiksi mistä ja miten materiaalit ovat tuotettu, miten ihmis- ja eläinoikeudet on otettu huomioon ja kuinka ympäristöä suojelevia säännöksiä on noudatettu (Väänänen, Vartiainen, Kaipainen, Pitkäniemi \& Pöllänen, 2018; Väänänen ym., 2017; myös Zhan \& Walker, 2018). 
Kestävä käsityö tuotteena sulkee sisälleen ominaisuuksia, jotka voivat olla käsin kosketeltavia kuten materiaalit, design, tekniikka, laatu, tai abstrakteja kuten tuotesuhde tai elinkaari, tai niiden yhdistelmänä estetiikka ja tarve (mm. Na, 2017; Nugraha, 2012; Risatti, 2007). Väänäsen ja muiden (2017) tutkimuksessa käsityöntekijät kuvasivat laadun käsin kosketeltavaksi, mutta sen voidaan katsoa syntyvän materiaalien, suunnittelun ja teknisten ratkaisujen pohjalta (vrt. Koskennurmi-Sivonen \& Anttila, 2008). Kestävän käsityön aineettomat näkökulmat nousevat esiin kahden elementin, tuotteen ja toiminnan, mukana. Näitä ovat sosiaaliset, taloudelliset, yhteiskunnalliset, kulttuuriset, psykologiset, filosofiset, vuorovaikutukselliset ja ympäristön näkökulmat (Kokko \& Dillon, 2011; Luutonen, 2013; Risatti, 2007; Seitamaa-Hakkarainen ym., 2007; Sennett, 2008). Kestävä käsityö syntyy käsissä materiaalisista aineksista, mutta aineeton käsityö sitoo sen ympäristöön kokonaisuudessaan, tuo tuotteelle ja tekemiselle erilaisia merkityksiä, jotka heijastelevat vuorovaikutuksessa muun muassa kulttuuria, tekemisen ja tuottamisen muotoa tai periaatteita, joista ei haluta tinkiä. Näkökulmat nousevat esiin erityisesti reflektion noustessa abstraktille tasolle.

Ensimmäinen, lähes intuitiivinen tapa lähestyä kestävää käsityötä on materiaalinen, jolloin tarkastellaan tuotetta ja materiaaleja miettien niiden ympäristövaikutuksia (Väänänen ym., 2018). Kun pohdiskelu siirtyy tuotteesta ihmiseen ja toimintaan, muuttuu lähestyminen toiminnan tarkasteluksi, esimerkiksi siihen, miten voisin toimia niin, että ottaisin paremmin huomioon erilaiset tuotteen ominaisuudet. Nämä lähestymistavat ovat konkreettisia keinoja lähestyä kestävää käsityötä. Aineeton lähestyminen kestävään käsityöhön ilmenee, kun ajattelussa siirrytään abstraktille tasolle ja havahdutaan pohtimaan tekijää ja tuotetta ympäröiviä asioita, kuten käsityötä kulttuurisena ilmiönä tai perinnekäsityönä tai käsityön kasvatuksellista tehtävää. Tätä lähestymistapaa voidaan kutsua sosiokulttuuriseksi lähestymistavaksi. Toisin sanoen, mitä syvemmin käsityöntekijä tuntee materiaalinsa ja toimintansa ja niiden seuraukset tai vaikutukset, sitä reflektiivisemmin hän lähestyy kestävää käsityötä (vrt. Bayliss \& Dillon, 2010; Bennet, 2010).

\section{Kestävä käsityö perusopetuksen käsityössä}

Käsityön erityinen kasvatuksellisuus perusopetuksen oppiaineena perustuu kokonaiseen käsityöprosessiin (Kojonkoski-Rännäli, 2005) sekä monimateriaalisesti teknisen työn, teknologian, muotoilun ja tekstiilityön sisältöjen monipuoliseen opiskeluun (Pöllänen, 2020; Pöllänen \& Pöllänen, 2019). Perusopetuksen opetussuunnitelman perusteiden (Opetushallitus, 2014) mukaan käsityö on kaikille oppilaille yhteinen oppiaine viittaamatta oppilaiden sukupuoleen. Näin käsityössä sekä tekstiilityön että teknisen työn sisällöt tarjoavat yhdenvertaisen mahdollisuuden kestävän käsityön opiskeluun.

Eri ammateissa tarvitaan edelleen käden taitoja, myös vaativimmissa erikoistuneissa robotiikkaa ja automaatiota hyödyntävissä ammateissa taituroivaa motoriikkaa, jota voidaan kehittää erityisen hyvin 7-vuotiaasta 14-vuotiaaksi (Prechtl, 1993). Motoristen taitojen saavuttamiseen tarvitaan eri ruumiinosien koordinaatiota ja useiden eri aisti-, havainto- ja 
Ainedidaktiikka 5(2) (2021)

kognitiivisten prosessien välistä vuorovaikutusta (Piek, 2006). Karkea- ja hienomotorisen harjoituksen vaikutuksia koskevat tutkimukset ovat yksiselitteisesti osoittaneet motorisen harjoituksen myönteiset vaikutukset lapsen tiedolliseen kehitykseen (Bjorklund \& Brown, 1998; Hellendoom, Wijnroks, von Daalen, Dietz, Buitelaar \& Lesemanet, 2015; Zeng, Ayyub, Sun, Wen, Xiang \& Gao, 2017). Nämä vaikutukset ilmenevät lapsen lisääntyneinä oppimisedellytyksinä, taitona hankkia, käsitellä ja varastoida tietoa sekä käyttää kieltä.

Teollisista tuotantomenetelmistä huolimatta tarvitsemme käsiämme, kehoamme ja aivojamme toimimaan tasapainoisessa yhteistyössä; käsitöiden tekeminen aktivoi molempia aivopuoliskoja (Huotilainen, 2019). Käsityötehtävien kolmiulotteisuus ja materiaalisuus haastavat luovuuteen ja ongelmanratkaisuun sekä pitkäjänteiseen sitkeään projektimaiseen työntekoon aidoissa suunnittelu- ja valmistustehtävissä. Tuotteen valmistusprosessin lisäksi käsityössä opitaan ideointi-, suunnittelu- ja ongelmanratkaisutaitoja sekä tuotteen ja sen laadun, että oman toiminnan reflektoivaa arviointia (Pöllänen, 2020). Kun käsin tekeminen on tekijälle läheistä ja reflektio monipuolista, voidaan lähestymistä kuvata kokonaisvaltaiseksi niin, että käsityötä kuvataan kestävän käsityön kaikista näkökulmista. Tämä tarkoittaa käytännössä sitä, että oppilaiden taitojen kehittyessä myös reflektion taito kehittyy ja he oppivat ymmärtämään muun muassa tuotesuunnittelun lähtökohtia (ks. Papanek, 1995) ja oman toimintansa laajempia merkityksiä (ks. Schön, 1991). Monialaisen yhteiskehittelyn, pohdintojen ja monimateriaalisen käsityön mahdollisuuksien yhdistäminen oppilaiden omaan elämismaailmaan nivottuihin teemoihin osallistaa ja sitouttaa yhteisölliseen työskentelyyn sekä antaa mahdollisuuden harjoitella vaikuttamista konkreettisen tutkimisen ja tekemisen avulla (ks. Lindström ym., 2014, Räisänen ym., 2014).

Vastuullisten ja ympäristömyötäisyyden huomioon ottavien kuluttajien sekä kulttuurin kontekstin huomioivien kansalaisten (Markkula, 2011) kasvatuksessa käsityönopetuksella on ollut (Komiteanmietintö, 1952) ja on edelleen selkeä paikkansa (ks. Opetushallitus, 2014, Räisänen ym., 2014). Käsityön ja kestävän kulutuksen ideologiasta lähtevä käsityön opetus voi tiedostavaan kuluttajuuteen kasvattamisena olla vastareaktio kulutuskeskeisyydelle, jossa nähdään, että runsas kulutus on hyväksi ihmiselle ja taloudelle (vrt. Salonen, 2019). Tiedostava kuluttajuus rakentuu ymmärrykselle harkitsevasta ostokäyttäytymisestä sekä taitoon käyttää ja huoltaa tuotteita niin, että niiden käyttöikä pitenee. Käsityöprosessin myötä oppilas oppii erottamaan valmiin tuotteen tuotantovaiheita ja saa teknologista yleissivistystä, jolloin hän myös pystyy kriittisesti arvioimaan niiden ympäristövaikutuksia. Käsityötuotteen elinkaaren opettaminen on yksi perustavaa laatua olevia sisältöjä (vrt. Kokko \& Räisänen, 2019; Räisänen ym., 2014). Elinkaari tai sen syklisyys avaa myös mahdollisuuden luovalle ajattelulle, kun oppilaat pohtivat yhdessä tuotteelle uusia käyttötarkoituksia tai hyödyntävät käytettyjä materiaaleja uuteen käyttöön edistäen kiertotalous-ajattelua. Käsityön opetuksen eri sisällöissä voidaan oppilaita herätellä ajattelemaan kriittisesti, lisätä tietoisuutta eettisistä ja kestävyyteen liittyvistä haasteista sekä ohjata vastuulliseen toimintaan, esimerkiksi erilaisten suunnittelutehtävien, materiaalitietouden tai ympäristömerkkien avulla (Räisänen ym., 2014). Tiedonhankinta voi toimia myös eriyttävänä 
(Landrum \& McDuffie, 2010) muiden tehtävien lomassa luoden tunneille rakennetta ja samalla kartuttaen käsityötietoa.

Käsityössä kestävyyskasvatus on Perusopetuksen opetussuunnitelman perusteiden (Opetushallitus, 2014) mukaan sitoutunut kulttuuriperinnön huomioimiseen paikallisella, kansallisella ja globaalilla tasolla (ks. Laine, 2019). Kestävä käsityö -käsitteenä on kuitenkin laajempi kuin ainoastaan osaaminen kulttuuriperinnön merkityksestä katsottuna. Kulttuuri laajempana, kaikkeen ihmisten toimintaan ja tuotoksiin liittyvänä käsitteenä avaa ymmärryksen myös nykyiseen kulttuurin uudistamiseen. Käsityön merkitys inhimillisen tekemisen ja psyko-sosiaalisen hyvinvoinnin lähteenä (Kojonkoski-Rännäli, 2014; Pöllänen, 2015a, 2015 b) voi olla yksi osa pehmeille arvoille rakentuvaa osallistuvaa kulttuuria.

Koska kestävä käsityö sisältää laajan kokonaisuuden eri teemoihin liittyviä asioita, voisi kestävää käsityötä käsitellä laaja-alaisena oppimiskokonaisuutena, jossa tehdään myös yhteistyötä eri alojen toimijoiden ja lähiyhteisöjen kanssa. Perusopetukseen sovellettuna kestävä käsityö toimintana, tuotteena ja aineettomana käsityönä voidaan pilkkoa osiin ja tarkastella yksityiskohtaisesti kokonaisuuden palasia integroiden myös eri oppiaineiden sisältöihin. Konkreettinen toiminta sekä tekemisen myötä havainnollistuva tiedon välittäminen ja arvojen pohtiminen (ks Räisänen ym., 2014) voi tukea ekologisen kädenjäljen rakentamista. Perusopetuksessa kestävän käsityön systeemisyyden hahmottaminen perustuu oman toiminnan ja kestävän kädenjäljen merkityksen ymmärtämiselle.

\section{Pohdinta}

Keskustelu kestävästä kehityksestä on useiden asiantuntijoiden mukaan konkretisoitumatta, jolloin ratkaisuja käytännön toimiin poliittisella, yhteiskunnallisella, kulttuurisella, sosiaalisella, taloudellisella ja yksilötasolla on esitetty suhteellisen vähän (Ehrenfeld, 2008; Häikiö, 2005; Ivanaj \& Ivanaj, 2010; Salonen, 2010). Systeemisyyden ymmärtäminen voi tarjota näkökulman, josta voidaan tarkastella kestävyyttä toimintana niin mikro- kuin meso-tasolla (Gaziulusoy \& Brezet, 2015). Kestävän käsityön tavoitteena onkin ylläpitää (engl. sustain) ja suojata (engl. safeguard) käsityötoimintaa niin yksilön, yhteiskunnan kuin myös kulttuurin tasolla.

Kestävä käsityö positiivisiin tekoihin rohkaisevana kädenjälkiajattelutapana ja konkreettisena toimintana merkitsee taitoa, joka syventää käsityötietoa sekä arvoja ja asenteita. Käsin tekemisen hyvinvointimerkitysten (Pöllänen, 2015a, 2015b) lisäksi kestävä käsityötuote huomioi materiaalien, elinkaaren, tekniikan, designin, laadun, esteettisyyden, tarpeen ja tuotesuhteen. Kädenjälki-näkökulmasta yksilö voi vähentää käsityötuotteiden valmistuksen ja käytön tuottamaa jalanjälkeä ja tukea tuotteen hyvien ominaisuuksien lisäarvolla kestävyyttä tähtäävää toimintaansa. Aineeton käsityö nivoo kestävyyden ympäristön lisäksi kulttuuriin sekä sosiaaliseen, taloudelliseen, psykologiseen, yhteiskunnalliseen, filosofiseen, ja kommunikatiiviseen näkökulmaan. Nämä elementit toimivat lomittain yhdessä muotoillen ympäristöä, konkreettista tuotteita sekä tekoja kestäväksi ekologiseksi kädenjäljeksi. Konkreettisesti kestävyys 
Ainedidaktiikka 5(2) (2021)

tulee yksilötasolla näkyväksi ympäristömyötäisyytenä muun muassa elinkaariajatteluna, kestävien tuotteiden, kierrättämisen, tuotteiden uusiokäytön ja hitaan muodin myötä (Räisänen ym., 2014; Väänänen \& Pöllänen, 2020; Väänänen, 2020). Käsityöntekijä tekee aina päätöksiä, joilla on vaikutuksia tuotteeseen, toimintaan ja ympäristöön. Tärkeintä kestävässä käsityössä onkin käsityöntekijän tekijän arvot ja asenteet, jotka muokkaavat käsityötä ja toimintaa kestävään suuntaan (Räisänen ym., 2014; Suojanen, 2001). Kestävän kulutuksen ideologiasta lähtevä käsityö voi olla myös tiedostavaan kuluttajuuteen kasvattamista siten, että työn ja tuotteen laadun arvostus ja teknologinen yleissivistys tukevat kestävien arvojen omaksumista.

Käsityönopetuksessa toiminnallisuus ja integrointi arjessa ilmeneviin tiede- ja oppiainerajat ylittäviin kestävyyden haasteisiin mahdollistaa usealla eri tavalla ja tasolla kestävän kehityksen periaatteiden huomioimisen. Kestävä kehitys opetussuunnitelman kantavana teemana ohjaa opetusja kasvatusorganisaatioita oppimaan ja löytämään keinoja toteuttaa kestävän kehityksen eri osa-alueet huomioivaa opetusta kaikille oppilaille niin, että tavoitteena on kestävyyteen pyrkivä aktiivinen maailmankansalaisuus sekä osallistava yhteisö. Kestävä kulttuuri ja käsityö sen yhtenä osaalueena niin tuotteen, toiminnan kuin oppiaineenkin näkökulmasta rakentuu oppimiseen perustuvalle taito- ja tietopääomalle, jota voi eritellä kestävän käsityön määrittelyn kautta systeemisenä kokonaisuutena tai yksitellen osa-alueittain. Opetus ja kasvatus nähdäänkin parhaimpana keinona muutokseen ja kestävään tulevaisuuteen (Unesco, 2018), myös organisaatiot voivat kehittyä oppimalla (Rainey \& Kolb, 2014). Käytännössä käsityön opetuksen organisointi (Jaatinen \& Lindfors, 2016), opettajan (Lindfors \& Pirttimaa, 2018) ja oppilaiden (Hilmola \& Autio, 2017; Metsärinne \& Kallio, 2016) asenteet ovat ratkaisevassa asemassa opetuksen toteuttamisessa ja siinä, miten se ohjaa kestävään tulevaisuuteen.

Kädenjälki-metaforan mukaisesti kestävä käsityö voi rohkaista kestävyyttä tukevaa ajattelutapaa ja toimintaa, auttaa analysoimaan toiminnan tuottamaa jalanjälkeä niin, että se huomioi myös valittujen toimien positiiviset vaikutukset tai auttaa siirtämään analyysin muihin toimintoihin ja lopuksi ohjaa vaihtoehtoisiin kestävien periaatteiden mukaisiin käytännön toimiin (ks. Guillaume ym., 2020). Kestävä käsityö toimintana, tuotteena ja aineettomana käsityönä ja sen ymmärtäminen välineenä (engl. instrumental) voi auttaa saavuttamaan kestävää elämäntapaa ja hyvinvointia monella yhteiskunnan osa-alueella. Osiin pilkottuna se voi auttaa kestävän käsityön kokonaisuuden ja kestävyyden systeemisyyden hahmottamisessa ja näiden esiintuomisessa osana käsityön opetusta kaikilla koulutusasteilla. Kestävä kädenjälki -metaforan toivotaan tarjoavan sekä teoreettista että käytännöllistä merkitystä sisältäviä näkökulmia käsityön opetuksesta käytävään keskusteluun. Alan tutkimukseen se voi tarjota positiiviselle lähestymistavalle perustuvan käsitteellisen viitekehyksen. 


\section{Ainedidaktiikka 5(2) (2021)}

\section{Lähteet}

Aakko, M. (2013). Kestävyys muodissa. Katsaus kestävän muodin kokonaisuuteen. Teoksessa R. Koskennurmi-Sivonen (toim.), Johdatuksia pukeutumisen tutkimukseen (s. 133-157). Tekstiilikulttuuriseuran julkaisuja 6. Helsinki: Tekstiilikulttuuriseura. http://hdl.handle.net/10138/39202

Bayliss, P. \& Dillon, P. (2010). Cosmologies and lifestyles a cultural ecological framework and its implications for education systems. Anthropological Journal of European Cultures, 19(2), 7-21. https://doi.org/10.3167/ajec.2010.190202

Bennett, J. (2015). Trends in craft education and the value attached to craft. Making Futures Journal, 4. https://makingfuturesarchive.pca.ac.uk/archive/mfjournal2015/thematic-sessionsmf15

Biemer, J., Dixon, W. \& Blackburn, N. (2013). Our environmental handprint. The good we do. Institute of electrical and electronic engineers. 1st IEEE Conference on Technologies for Sustainability (SusTech), 146-153. https://doi.org/10.1109/SusTech.2013.6617312

Bjorklund, D. F. \& Brown, R. D. (1998). Physical play and cognitive development: Integrating activity, cognition, and education. Child Development, 69(3), 604 606. https://doi.org/10.1111/j.1467-8624.1998.tb06229.x

von Busch, O. (2010). Exploring net political craft: From collective to connective. Craft Research, 1(1), 113-124. https://doi.org/10.1386/crre.1.113 7

von Busch, O. (2018). Inclusive fashion - an oxymoron - or a possibility for sustainable fashion? Fashion Practice, 10(3), 311-327. https://doi.org/10.1080/17569370.2018.1507145

von Busch, O. \& Palmås, K. (2016). Designing consent: Can design thinking manufacture democratic capitalism? Organizational Aesthetics, 5(2), 10-24. Haettu osoitteesta: https://oa.journals.publicknowledgeproject.org/index.php/oa/article/view/66

Ceschin, F. \& Gaziulusoy, I. (2016). Evolution of design for sustainability: From product design to design for system innovations and transitions. Design Studies, 47, 118163. https://doi.org/10.1016/j.destud.2016.09.002

Corkhill, B., Hemmings, J., Maddock, A. \& Riley, J. (2014). Knitting and well-being. Textile: The Journal of Cloth and Culture, 12(1), 34-57. https://doi.org/10.2752/175183514x13916051793433

Coughlan, M., Cronin, P. \& Ryan, F. (2013). Doing a literature review in nursing, health and social care. London: SAGE.

Dillon, P. \& Kokko, S. (2017). Craft as cultural ecologically located practice: Comparative case studies of textile crafts in Cyprus, Estonia and Peru. Craft Research, 8(2), 193-222. https://doi.org/10.1386/crre.8.2.193 1

Dissanayake, E. (1995). Homo aestheticus: Where art comes from and why. Seattle: University of Washington.

Dormer, P. (1994). The art of the maker. London: Thames and Hudson Ltd.

Ehrenfeld, J. R. (2008). Sustainability by design: A subversive strategy for transforming our consumer culture. New Haven, Conn.; London: Yale University Press.

Ehrenfeld, J. R. (2014). The real challenge of sustainability. Teoksessa K. Fletcher \& M. Tham (toim.), Routledge handbook of sustainability and fashion (s. 57-63). London and New York: Routledge.

Farrer, J. M. \& Watt, C. A. (2015). The true value of materials: BRIDGE (Building research and innovation deals for the green economy). Textiles and Clothing Sustainability, 1(10), 1-14. https://doi.org/10.1186/s40689-015-0010-1

Fletcher, K. (2008). Sustainable fashion \& textiles. London: Earthscan.

Gaziulusoy, A. I. \& Brezet, H. (2015). Design for system innovations and transitions: a conceptual framework integrating insights from sustainability science and theories of system innovations and transitions. Journal of Cleaner Production, 108, Part A, 558-568. https://doi.org/10.1016/j.jclepro.2015.06.066

Garber, E. (2013). Craft as activism. The Journal of Social Theory in Art Education, 33(1), 53-66. Haettu osoitteesta: https://scholarscompass.vcu.edu/jstae/vol33/iss1/6/

Greer, B. (2014). Craftivism. The art of craft and activism. Vancouver: Arsenal Pulp.

Grogan, S. (2008). Body image: Understanding body dissatisfaction in men, women and children. New York: Routledge. 


\section{Ainedidaktiikka 5(2) (2021)}

Groth, C. (2017). Making sense through hands - Design and craft practice analysed as embodied cognition. (Väitöskirja). Aalto University. http://urn.fi/URN:ISBN:978-952-60-7130-5

Guillaume, J., Sojamo, S., Porkka, M., Gerten, M., Jalava, M., Lankoski, L... \& Kummu, M. (2020). Giving legs to handprint thinking: foundations for evaluating the good we do. Earth's Future, 8(6). https://doi.org/10.1029/2019EF001422

Hayward, B. (2010). The social handprint: Understanding decentred citizen agency and UK UnCut. RESOLVE Working Paper 06-10. Haettu osoitteesta http://resolve.sustainablelifestyles.ac.uk/sites/default/files/resolve_wp_06-10.pdf

Hellendoom, A., Wijnroks, L., von Daalen, E., Dietz, C., Buitelaar, J. K. \& Leseman, P. (2015). Motor functioning, exploration, visuospatial cognition and language development in preschool children with autism. Research in Development Disabilities, 39, 32-42. https://doi.org/10.1016/j.ridd.2014.12.033

Hilmola, A. \& Autio, O. (2017). Käsityö ja asenteet - oppiaineen tulevaisuus. Ainedidaktiikka, 1(1), 39-59. https://doi.org/10.23988/ad.v1i1.60731

Huotilainen, M. (2019). Näin aivot oppivat. Jyväskylä: PS-Kustannus.

Häikiö, L. (2005). Osallistumisen rajat. Valta-analyysi kestävän kehityksen suunnittelusta Tampereella. (Väitöskirja). Tampereen yliopisto. https://urn.fi/urn:isbn:951-44-6256-4

Ihatsu, A.-M. (2002). Making sense of contemporary American craft. (Väitöskirja). Joensuun yliopisto.

Ivanaj, V. \& Ivanaj, S. (2010). The contribution of interdisciplinary skills to the sustainability of business: When artists, engineers, and managers work together to serve enterprises. Teoksessa J. A. Stoner \& C. Wankel (toim.), Global sustainability as a business imperative (s. 91-110). New York: Palgrave MacMillan.

Jaatinen, J. \& Lindfors, E. (2016). Yhteisopetus käsityössä. Teoksessa H. Pakula, E. Kouki, H. Silfverberg \& E. Yli-Panula (toim.), Uudistuva ja uusiutuva ainedidaktiikka (s. 13-27) Ainedidaktisia tutkimuksia 11. Suomen ainedidaktinen tutkimusseura ry. http://hdl.handle.net/10138/174336

Kokko, S. \& Dillon, P. (2011). Crafts and craft education as expressions of cultural heritage: individual experiences and collective values among an international group of women university students. International Journal of Technology and Design Education, 21(4), 487-503. https://doi.org/10.1007/s10798-010-9128-2

Kokko, S. \& Kaipainen, M. (2015). The changing role of cultural heritage in traditional textile crafts from Cyprus. Craft Research, 6(1), 9-30. https://doi.org/10.1386/crre.6.1.9 1

Kokko, S. \& Räisänen, R. (2019). Craft education in sustaining and developing craft traditions - Reflections from Finnish craft teacher education. Techne Series Research in Sloyd Education and Craft Science A, 26(1), 27-43. https://journals.oslomet.no/index.php/techneA/article/view/2911

Kojonkoski-Rännäli, S. (2005). Pohdintoja käsityö-oppiaineesta. Haettu osoitteesta https://web.archive.org/web/20050323204258/http://www.edu.fi/page.asp?path=498,1329,152 $7,21844,37187$

Kojonkoski-Rännäli, S. (2014). Käsin tekemisen filosofia. Rauma: Turun yliopiston opettajankoulutuslaitos, Rauman yksikkö.

Komiteanmietintö. (1952). Kansakoulun opetussuunnitelmakomitean mietintö: Varsinaisen kansakoulun opetussuunnitelma. Helsinki: Valtioneuvosto.

Koskennurmi-Sivonen, R. \& Anttila, M. (2008). Käsityö, laatu ja kestävä kehitys. Teoksessa J. Lavonen (toim.), Tutkimusperustainen opettajankoulutus ja kestävä kehitys: Ainedidaktinen symposiumi Helsingissä 3.2.2006 (s 299-308). Helsinki: Käyttäytymistieteellinen tiedekunta, Helsingin yliopisto.

Kouhia, A. (2015). The Making-Of: An autoethnographic cinema on the meanings of contemporary craft practicing for a young hobbyist. Textile, 13(3), 266-283. https://doi.org/10.1080/14759756.2015.1084788

Kuusk, K., Wensveen, S. A. \& Tomico Plasencia, O. (2016). Craft qualities translated from traditional crafts to smart textile services. Studies in Material Thinking, 14(5), 1-21. https://www.materialthinking.org/papers/223

König, A. (2013). A stitch in time: Changing cultural constructions of craft and mending. Culture Unbound, 5(4), 569-585. https://doi.org/10.3384/cu.2000.1525.135569 


\section{Ainedidaktiikka 5(2) (2021)}

Laine, M. H. (2019). Koulu kulttuuri-identiteetin tukijana. Ainedidaktiikka, 3(1), 21-42. https://doi.org/10.23988/ad.72962

Landrum, T. J. \& McDuffie, K. A. (2010). Learning Styles in the Age of Differentiated Instruction. Exceptionality: A Special Education Journal, 18(1), 6-17. https://doi.org/10.1080/09362830903462441

Leal Filho, W., Manolas, E., \& Pace, P. (2015). The future we want. International Journal of Sustainability in Higher Education, 16(1), 112-129. https://doi.org/10.1108/IJSHE-03-2014-0036

Le, T. H., Tran, V. T., Le, Q. V., Nguyen, T. P., Schnitzer, H. \& Braunegg, G. (2016). An integrated ecosystem incorporating renewable energy leading to pollution reduction for sustainable development of craft villages in rural area: A case study at sedge mats village in Mekong Delta, Vietnam. Energy, Sustainability and Society, 6(21), 1-12. https://doi.org/10.1186/s13705-016-0088-6

Lindfors, E. \& Pirttimaa, M. (2018). Teknologiakasvatuksen haasteet ja mahdollisuudet automaatioteknologian oppimisympäristössä. Ainedidaktiikka, 2(1), 2-19. https://doi.org/10.23988/ad.60823

Lindström, K. \& Ståhl, Å. (2014). Patchworking publics-in-the-making. design, media and public engagement. School of arts and communication K3. (Väitöskirja). Malmö University. urn:nbn:se:mau:diva-7401

Luutonen, M. (2007). New craft policy in Finland. The Design Journal, 10(2), 49-61. https://doi.org/10.2752/146069207789272640

Luutonen, M. (2013). Käsityö- ja muotoilualan yrittäjä 2013. Helsinki: Käsi- ja taideteollisuusliitto Taito ry.

Markkula, A. (2011). Consumers as ecological citizens in clothing markets. (Väitöskirja). Aalto University. http://urn.fi/URN:ISBN:978-952-60-4064-6

Metsärinne, M. \& Kallio, M. (2016). How students' attitudes related to learning outcomes? International Journal of Technology and Design Education, 26(3), 353371. https://doi.org/10.1007/s10798-015-9317-0

Muya, M., Price, A. D. \& Edum-Fotwe, F. T. (2006). Construction craft skills requirements in sub-Saharan Africa: A focus on Zambia. Engineering, Construction and Architectural Management, 13(3), 223-241. https://doi.org/10.1108/09699980610669660

$\mathrm{Na}, \mathrm{Y}$. (2012). Craftology: Redefining contemporary craft in culture, people and sustainability. (Väitöskirja). Aalto University. http://urn.fi/URN:NBN:fi:aalto-201604111721

Nugraha, A. (2012). Transforming Tradition: A method for maintaining tradition in a craft and design context. (Väitöskirja). Aalto University. http://urn.fi/URN:NBN:fi:aalto-201604111721

Opetushallitus. (2014). Perusopetuksen opetussuunnitelman perusteet 2014. Helsinki: Opetushallitus.

Papanek, V. (1973). Turhaa vai tarpeellista? Helsinki: Kirjayhtymä.

Papanek, V. (1995). The Green Imperative. London: Thames and Hudson.

Paré, G. \& Kitsiou, S. (2017). Methods for Literature Reviews. Teoksessa F. Lau \& C. Kuziemsky (toim.), Handbook of eHealth Evaluation: An Evidence-based Approach (s. 158-180). Victoria, BC: University of Victoria.

Parts, P.-K., Rennu, M., Jääts, L., Matsin, A. \& Metslang, J. (2011). Developing sustainable heritage-based livelihoods: An initial study of artisans and their crafts in Viljandi County, Estonia. International Journal of Heritage Studies, 17(5), 401-425. https://doi.org/10.1080/13527258.2011.589199

Piek, J. P. (2006). Infant motor development. Champaign, IL: Human Kinetics. https://doi.org/10.5040/9781492596943

Prechtl, H. F. R. (1993). Principles of early motor development in the human. Teoksessa A. F. Kalverboer, B. Hopkins, R. Geuze \& R. Magnusson (toim.), Motor development in early and later childhood (s. 35-50). Cambridge: University Press.

Pöllänen, S. (2015a). Elements of crafts that enhance well-being. Journal of Leisure Research, 47(1), 58-78. https://doi.org/10.1080/00222216.2015.11950351

Pöllänen, S. H. (2015b). Crafts as leisure-based Coping: Craft makers' descriptions of their stress-reducing activity. Occupational Therapy in Mental Health, 31(2), 83100. https://doi.org/10.1080/0164212X.2015.1024377

Pöllänen, S. H. (2020). Perspectives on Multi-Material Craft in Basic Education. The International Journal of Art and Design Education, 39(1), 255-270.

https://doi.org/10.1111/jade.12261 


\section{Ainedidaktiikka 5(2) (2021)}

Pöllänen, S. \& Kröger, T. (2000). Käsityön erilaiset merkitykset opetuksen perustana. Teoksessa J. Enkenberg, P. Väisänen \& E. Savolainen (toim.), Opettajatiedon kipinöitä (s. 233-253). Joensuu: Joensuun yliopisto. http://sokl.uef.fi/verkkojulkaisut/kipinat/

Pöllänen, S. H. \& Pöllänen, K. M. (2019). Beyond programming and crafts: Towards computational thinking in basic education. Design and Technology Education: an International Journal, 24(1), 13-32. https://ojs.lboro.ac.uk/DATE/article/view/2566

Pöllänen, S. \& Urdzina-Deruma, M. (2017). Future-oriented reform of craft education: The cases of Finland and Latvia. Teoksessa E. Kimonen \& R. Nevalainen (toim.), Reforming teaching and teacher education: Bright prospects for active schools (s. 117-144). Rotterdam, NL: Sense Publishers. https://doi.org/10.1007/978-94-6300-917-1_5

Rainey, M. A. \& Kolb, D. A. (2014). Organization leadership. Leading in a learning way. Teoksessa B. B. Jones \& M. Brazzel (toim.), The NTL handbook of organization development and change (s. 329-347). San Francisco: Wiley. https://doi.org/10.1002/9781118836170.ch16

Risatti, H. (2007). Theory of Craft: Function and Aesthetic Expression. Chapel Hill: University of North Carolina Press.

Räisänen, R., Kouhia, A. \& Kärnä-Behm, J. (2014). Kestävyys ja käytettävyys käsityön suunnittelussa. Teoksessa A. Nuutinen, P. Fernström, S. Kokko, \& H. Lahti (toim.), Suunnittelusta käsin - Käsityön tutkimuksen ja opetuksen vuoropuhelu (s. 52-66). Kotitalous- ja käsityötieteiden julkaisuja, No. 36. Helsinki: Käyttäytymistieteellinen tiedekunta, Helsingin yliopisto. http://hdl.handle.net/10138/153027

Räisänen, R. \& Laamanen, T-K. (2014). Tieto, kritiikki, toiminta, vastuu - pohdintaa kestävän kehityksen ja eettisen kuluttamisen näkökulmista käsityössä. Teoksessa S. Karppinen, A. Kouhia \& E. Syrjäläinen (toim.), Kättä pidempää-Otteita käsityön tutkimuksesta ja käsitteellistämisestä (s. 48-61). Helsinki: Käyttäytymistieteellinen tiedekunta, Helsingin yliopisto. http://hdl.handle.net/10138/43167

Saari, A. \& Värri, V-M. (2017). Outoja muukalaisia: Hyperobjektien aika ympäristökasvatuksen haasteena. Kasvatus, 48(5), 403-248.

Salonen, A. O. (2010). Kestävä kehitys globaalin ajan hyvinvointiyhteiskunnan haasteena. (Väitöskirja). Helsingin yliopisto. http://urn.fi/URN:ISBN:978-952-10-6535-4

Salonen, A. O. (2019). Transformative responses to sustainability. Teoksessa W. Leal Filho (toim.), Encyclopedia of sustainability in higher education (s. 1972-1979). Cham: Springer. https://doi.org/10.1007/978-3-319-63951-2 501-1

Salonen, A. O. \& Bardy, M. (2015). Ekososiaalinen sivistys herättää luottamusta tulevaisuuteen. Aikuiskasvatus, 35(1), 4-15. https://doi.org/10.33336/aik.94118

Schön, D. A. (1991) The reflective turn: Case Studies in and on educational practice, New York: Teachers Press, Columbia University.

Seitamaa-Hakkarainen, P., Pöllänen, S., Luutonen, M., Kaipainen, M., Kröger, T., Raunio, A.-M.,. . . \& Heinonen, A. (2007) (toim.), Käsityötieteen ja käsityömuotoilun sekä teknologiakasvatuksen tutkimusohjelma Savonlinnan opettajankoulutuslaitoksessa. Joensuu: Joensuun yliopisto. http://urn.fi/URN:ISBN:978-952-219-004-8

Sennett, R. (2008). The Craftsman. London: Penguin books.

Sherburne, A. (2009). Achieving sustainable textiles: A designer's perspective. Teoksessa R. S. Blackburn (toim.), Sustainable textiles Life cycle and environmental impact (s. 3-32). Oxford: Woodhead. https://doi.org/10.1533/9781845696948.1.3

Sung, K. \& Cooper, T. (2015). Sarah Turner - eco-artist and designer through craftbased upcycling. Craft Research, 6(1), 113-122. https://doi.org/10.1386/crre.6.1.113_1

Suojanen, U. (2001). Kestävä kehitys. Haettu osoitteesta: https://web.archive.org/web/20121031063625/http://www.kaspaikka.fi/keke/kestava_kehitys.doc

Soini-Salomaa, K. (2013). Käsi- ja taideteollisuuden ammatillinen tulevaisuus: Lokaalia käsityöläisyyttä vai globaalia designia? Futura, 32(4), 18-33.

Stuedahl, D. \& Mörtberg, C. (2012). Heritage knowledge, social media and the sustainability of the intangible. Teoksessa: E. Giaccardi (toim.), Heritage and social media. Understanding and experiencing heritage in a participatory culture (s. 107-126). London: Routledge. 


\section{Ainedidaktiikka 5(2) (2021)}

Tung, F.-W. (2012). Weaving with Rush: Exploring craft-design collaborations in revitalizing a local craft. International Journal of Design, 6(3), 71-84. http://www.ijdesign.org/index.php/IJDesign/article/view/1077

UNESCO (2018). Basic Texts of the 2003 Convention for the Safeguarding of the Intangible Cultural Heritage, 2018 Edition. Paris: Unesco. Haettu osoitteesta https://ich.unesco.org/doc/src/2003_Convention_Basic_Texts-_2018_versionEN.pdf

United Nations (2015). Transforming our world: The 2030 agenda for sustainable development A/RES/70/1. Haettu osoitteesta https://sustainabledevelopment.un.org/content/documents/21252030\%20Agenda\%20for\%20Sustainable $\% 20$ Development $\% 20$ web.pdf

Valtchanov, B.L., Parry, D.C., Glover, T.D. \& Mulcahy, C.M. (2016). 'A whole new world': Mothers' technologically mediated leisure. Leisure Sciences, 38(1), 50 67. https://doi.org/10.1080/01490400.2015.1043414

Vartiainen, L. (2010). Yhteisöllinen käsityö - Verkostoja, taitoja ja yhteisiä elämyksiä. (Väitöskirja). Itä-Suomen yliopisto. http://urn.fi/URN:ISBN:978-952-61-0088-3

Vartiainen, L. \& Kaipainen, M. (2012). Textile craft students' perceptions of sustainable crafts. Problems of Education in the 21st Century, 43, 131-140. https://doi.org/10.33225/pec/12.43.131

Väänänen, N. (2020). Sustainable craft. Dismantled and reassembled. (Väitöskirja). ItäSuomen yliopisto. http://urn.fi/URN:ISBN:978-952-61-3319-5

Väänänen, N. \& Pöllänen, S. (2020). Conceptualizing sustainable craft: Concept analysis of literature. The Design Journal, 23(2), 263-285. https://doi.org/10.1080/14606925.2020.1718276

Väänänen, N., Kaipainen, M., Sipilä, O., Turunen, V., Vartiainen, L., Kaasinen, J. \& Pöllänen, S. (2016). Kohti kestävää käsityötä. Teoksessa J. Heikkinen, A. Juvonen, K. Mäkitalo-Siegl, H. Nygren, \& T. Tossavainen (toim.), Taitoa, taidetta ja teknologiaa - kohti uutta opettajankoulutuksen mallia (s. 262-273). Joensuu: ItäSuomen yliopisto. http://urn.fi/URN:ISBN:978-952-61-2370-7

Väänänen, N., Pöllänen, S., Kaipainen, M., \& Vartiainen, L. (2017). Sustainable craft in practice: From practice to theory. Craft Research, 8(2), 257-284. https://doi.org/10.1386/crre.8.2.257 1

Väänänen, N., Vartiainen, L., Kaipainen, M., Pitkäniemi, H. \& Pöllänen, S. (2018). Understanding Finnish student craft teachers' conceptions of sustainability. International Journal of Sustainability in Higher Education, 19(5), 963-986. https://doi.org/10.1108/IJSHE-11-2017-0200

Wolfe Wilson, S. (2010). Towards sustainable craft Production in Jamaica. The Journal of Modern Craft, 3(2), 191-207. https://doi.org/10.2752/174967810X12774789403609

Wood, S. (2011). Sustaining craft and livelihoods: Handmade in India. Craft + Design Enquiry, 3, 89-100. https://doi.org/10.22459/CDE.03.2011.07

Yair, K. \& Schwarz, M. (2011). Making value: Craft in changing times. Cultural Trends, 20(3-4), 309-316. https://doi.org/10.1080/09548963.2011.589711

Zeng, N., Ayyub, A., Sun, H., Wen, H., Xiang, P. \& Gao, Z. (2017). Effects of physical activity on motor skills and cognitive development in early childhood: A systematic review. BioMed Research International, 2017, 1-13. $\underline{\text { https://doi.org/10.1155/2017/2760716 }}$

Zhan, X. \& Walker, S. (2018). Value direction: Moving crafts toward sustainability in the Yangtze River Delta, China. Sustainability, 10(4), 1-20. https://doi.org/10.3390/su10041252

Zhan, X., Walker, S., Hernandez-Pardo, R., \& Evans, M. (2017). Craft and sustainability: Potential for design intervention in crafts in the Yangtze River Delta, China. The Design Journal, 20(sup1), S2919-S2934. https://doi.org/10.1080/14606925.2017.1352802

Åhlvik, C. \& von Busch, O. (toim.) (2009). Handarbeta för en bättre värld. Jönköping: Jönköpings läns museum. 